\title{
Video-assisted versus open thoracotomy lobectomy: comparison on lymphadenectomy and survival in early stage of lung cancer
}

\author{
Dariusz A. Dziedzic ${ }^{1 \wedge}$, Marcin Zbytniewski $^{1 \wedge}$, Grzegorz M. Gryszko ${ }^{1 \wedge}$, Marcin M. Cackowski ${ }^{1 \wedge}$, \\ Renata Langfort ${ }^{2}$, Tadeusz M. Orlowski ${ }^{1}$; on behalf of the Polish Lung Cancer Study Group (PLCSG) \\ ${ }^{1}$ Department of Thoracic Surgery, National Research Institute of Chest Diseases, Warsaw, Poland; ${ }^{2}$ Department of Pathomorphology, National \\ Research Institute of Chest Diseases, Warsaw, Poland \\ Contributions: (I) Conception and design: DA Dziedzic; (II) Administrative support: TM Orłowski, R Langfort; (III) Provision of study materials or \\ patients: DA Dziedzic, M Zbytniewski, GM Gryszko, MM Cackowski; (IV) Collection and assembly of data: DA Dziedzic, M Zbytniewski, GM \\ Gryszko, MM Cackowski; (V) Data analysis and interpretation: DA Dziedzic, M Zbytniewski, GM Gryszko, MM Cackowski; (VI) Manuscript \\ writing: All authors; (VII) Final approval of manuscript: All authors. \\ Correspondence to: Dariusz A. Dziedzic. Department of Thoracic Surgery, National Research Institute of Chest Diseases, Plocka 26 Street, $01-138$ \\ Warsaw, Poland. Email: drdariuszdziedzic@gmail.com.
}

\begin{abstract}
Background: Video-assisted thoracic surgery (VATS) is increasingly used in the surgical treatment of early lung cancer, but the oncological benefits are still controversial. We aimed to compare videoassisted lobectomy and open thoracotomy lobectomy in terms of lymphadenectomy and long-term survival depending on the location of lobectomy.

Methods: A retrospective, multicenter study was based on the Polish Lung Cancer Study Group and included patients with stage I lung cancer who were surgically treated between 2007 and 2015. We included 1410 patients after video-assisted lobectomy and 4,855 after open thoracotomy.

Results: The average number of lymph nodes removed in video-assisted lobectomy was 10.9 and in open thoracotomy lobectomy was $12.9(\mathrm{P}<0.001)$. The 5-year survival was better in the video-assisted lobectomy group $(78.6 \%)$ compared to open thoracotomy $(73.8 \%)(\mathrm{P}=0.002)$. Significant differences were found in the case of left lower lobe and left upper lobe lobectomies. Multivariable analysis showed that the prognostic factors for open thoracotomy relative to video-assisted lobectomy are: age over 60 [HR (95\% CI): 1.55 (1.17-2.05), $\mathrm{P}=0.002$ ], female [HR (95\% CI): 1.57 (1.07-2.29), $\mathrm{P}=0.02$ ], squamous cell carcinoma [HR (95\% CI): 1.63 (1.12-2.37), $\mathrm{P}=0.011$ ], left lower lobe [HR (95\% CI): 2.69 (1.37-5.27), $\mathrm{P}=0.004$ ] and left upper lobe [HR (95\% CI): 1.53 (1.01-2.33), P=0.047].

Conclusions: The study showed that the number of lymph nodes removed during video-assisted lobectomy is significantly lower than in the open thoracotomy group. The long-term video-assisted lobectomy results were significantly better compared to open thoracotomy. Better long-term results were achieved on the left side of lobectomy.
\end{abstract}

Keywords: Lung cancer; video-assisted thoracic surgery (VATS); lobectomy; lymph node dissection (LND); open thoracotomy

Submitted Jun 19, 2020. Accepted for publication Oct 28, 2020.

doi: $10.21037 /$ jtd-20-2251

View this article at: http://dx.doi.org/10.21037/jtd-20-2251

\footnotetext{
^ ORCID: Dariusz A. Dziedzic, 0000-0002-3931-8636; Marcin Zbytniewski, 0000-0002-5507-8812; Grzegorz M. Gryszko, 0000-00024257-4470; Marcin M. Cackowski, 0000-0002-3183-6789.
} 


\section{Introduction}

Among all malignancies, lung cancer is responsible for the highest number of deaths in developed countries (1). In 2012, around 1.8 million new cases of lung cancer were diagnosed worldwide-this represents $12.9 \%$ of all malignancies (2). Lung cancer is currently the most common malignancy in Poland and is the major cause of death in oncology (20,000 patients each year). According to the National Cancer Registry data for 2013, lung cancer incidence accounted for $14 \%$ of all 156.5 thousand cases of malignant neoplasms among Polish patients (3). Importantly, lung cancer has also been the prime cause of cancer deaths among women for several years (3).

Patients with clinical stage I of lung cancer who underwent surgical resection within a month after diagnosis have admirable survival rate (92\%) (4). The American College of Chest Physicians recommends the video-assisted thoracic surgery (VATS) resection at stage I of lung cancer in experienced centers (5). VATS reduces postoperative pain, shortens hospitalization and results in a smaller percentage of complications (6). However, the oncological aspect (nodal staging) remains controversial (7). One crucial factor may be the number of lymph nodes removed that affect staging and distant results.

Although there have been many papers published regarding this topic and it seems that the issue is well defined, even American Surgeons with one of the best healthcare struggle in such important topic. Out of $45 \%$ lymph node resections reported as mediastinal lymph node dissection (LND), none of them meet pathological criteria for this kind of dissection (8). Also, up to $18 \%$ of node-negative resections are actually pNX (9). Hence, the problem of proper lymphadenectomy in surgery of NSCLC remains unsolved and need for further research continue to exist.

In this study, we aimed to assess the number of lymph nodes removed and the overall survival (OS) during VATS and open thoracotomy (TORA) lobectomies depending on the location of lobectomy.

We present the following article in accordance with the STROBE reporting checklist (available at http://dx.doi. org/10.21037/jtd-20-2251).

\section{Methods}

The material was collected retrospectively based on a database of the Polish Lung Cancer Study Group including information on patients in stage I non-small cell lung cancer operated on between January 2007 and September 2015 in 24 thoracic surgery centers in Poland. In our study, we included only patients with radical treatment (R0) and with at least 6 harvested lymph nodes from hilar and mediastinal stations according to the guidelines of the European Society of Thoracic Surgeons (10). Lymph node stations were determined based on The International Association for the Study of Lung Cancer lymph node map (11). We included all records from the database, that fulfilled the criteria. Later, we excluded middle lobe resection patients due to the small number of procedures. The 8 th edition of the TNM classification was used to determine staging (10). Because of the retrospective nature of our study, the selection bias is possible, but multicenter design and relatively large patient population reduce this risk. The study was conducted in accordance with the Declaration of Helsinki (as revised in 2013). The study was approved by the ethics committee of the National Research Institute of Chest Diseases, Warsaw, Poland (KB-89/2020); and written consent was obtained from all patients.

\section{Preoperative staging}

Preoperative tests included radiological examinations: chest $\mathrm{X}$-ray, computed tomography (CT), magnetic resonance imaging. If lymph nodes were larger than $10 \mathrm{~mm}$, patients had invasive diagnostic tests performed (endobronchial ultrasound with guided transbronchial needle aspiration, endoscopic ultrasound fine-needle aspiration, mediastinoscopy, mediastinotomy). Positron emission tomography CT (PET-CT) was not routinely performed at the beginning. In the period $2007-2010$ only $23 \%$ of patients had a PET-CT performed prior to the surgery, but from 2011 to 2015 this rate increased to $67 \%$.

\section{Follow-up}

Patients who received surgical treatment were consulted by a surgeon within $2-3$ weeks, then they were subject to follow-up tests (chest X-ray, CT, or PET-CT in justified cases) every 3 to 5 months for the period of 5 years. Patterns of failure were assessed by means of follow-up imaging studies and data obtained from procedures such as bronchoscopy, endobronchial ultrasound guided biopsy, endoscopic ultrasound fine-needle aspiration, transthoracic biopsy, mediastinoscopy, mediastinotomy. Hilar and/or mediastinal lymph node failures were defined as a new or 
enlarging lymph node measuring more than $10 \mathrm{~mm}$ on the short axis on CT or hypermetabolic on PET-CT imaging. This was consistent with disease progression in the patient's subsequent clinical follow-up. When patient's loss to followup occurred, patient's data were, in most cases, obtained from the Polish national personal identity number database to assess the survival. However, we excluded 167 patients from the study, because of incomplete data(mostly), loss of clinical information and insufficient period of follow-up.

\section{Risk factors}

The following factors were included in an analysis of risk factors: age, sex, histological type, staging, size, number of lymph nodes resected, complications rate, OS, and survival in each localization of lobectomy.

\section{Operative technique and complications}

The operations were performed under general anesthesia, with unilateral ventilation in the lateral position. The surgical technique of VATS was non-rib spreading incisions. VATS-lobectomy was made from 2 to 3 ports with utility incision in 4 th or 5 th intercostal space and a camera introduced through 8 th or 9 th intercostal space in the anterior or median axillary line. In the TORA-lobectomy group, muscle-sparing anterolateral thoracotomy was performed in the 4th or 5 th intercostal space. All patients underwent lymph nodes dissection with at least 3 mediastinal and 3 hilar nodes removed. Surgery complications included in analysis were as follows: hemorrhage (>800 $\mathrm{mL}$ ), prolonged air leakage (5-7 days), atrial fibrillation, pneumonia, prolonged intubation (>7 days), bronchial fistula. If surgeon converted technique from VATS-L to TORA-L, it was labeled as TORA-L.

\section{Statistical analysis}

Statistical analysis was performed on $\mathrm{R}$ ver. 3.0.2 [R Core Team(2013). R: A language and environment for statistical computing. R Foundation for Statistical Computing, Vienna, Austria. URL http://www.R-project.org/]. The distribution of continuous variables was first analyzed with Shapiro-Wilk test of normality and then according to the results $t$-student test or Mann-Whitney test was used. The significance level was set at 0.05 . The impact of clinical and pathological factors on OS were analyzed with the KaplanMeier method and log-rank tests were used to compare between categories in univariate analysis. To identify prognostic factors multivariable Cox proportional hazards model was used. A multivariable model was chosen by Akaike's information criterion in a stepwise algorithm.

\section{Results}

The study included 6,265 patients (2,620 women and 3,645 men) aged from 52 to 83 (mean 63.9 years). Median follow-up period for patients was 73.07 months. Stage IA2 was the most common in both groups: $50.9 \%$ in VATSlobectomy group and $48.9 \%$ in TORA-lobectomy group $(\mathrm{P}=0.064)$. Adenocarcinoma was the most frequent type of cancer in both VATS-lobectomy and TORA-lobectomy groups $(69.5 \%$ and $58.9 \%$ respectively; $\mathrm{P}<0.001)$. On the right side, stage IA2 was the most common in both groups: $21.3 \%$ in VATS-lobectomy group and $25.1 \%$ in TORAlobectomy group $(\mathrm{P}=0.175)$. On the left side, in the VATSlobectomy group, stage IA1 was found in $29.2 \%$ of patients, and in the TORA-lobectomy group only in $10.9 \%(\mathrm{P}=0.01)$. The lobectomy location distribution was comparable in both groups. Operations on the right side in the VATSlobectomy and TORA-lobectomy were performed on $55.7 \%$ and $58.3 \%$ of patients, respectively $(\mathrm{P}=0.175)$. Detailed patients' characteristics are presented in Table 1.

\section{Number of dissected lymph nodes}

The median of lymph nodes removed in the VATSlobectomy group was 7.69 (mean 10.9) and it was significantly lower than in the thoracotomy group (median 9.10; mean 12.9) $(\mathrm{P}<0.001)$ (Table 1). For N1 group, the median of removed lymph nodes for VATS-lobectomy and TORA-lobectomy were 4.0 and 5.0 respectively $(\mathrm{P}<0.001)$, and for $\mathrm{N} 2$ group 5.0 and $6.0(\mathrm{P}<0.001)$, respectively. Significant larger numbers of removed lymph nodes were found in the following stations in case of TORA-lobectomy: \#2R $(\mathrm{P}=0.013)$, \#3 ( $\mathrm{P}<0.001)$, \#3p $(\mathrm{P}=0.031)$, \#4R $(\mathrm{P}=0.001)$, \#4L $(\mathrm{P}<0.001)$, \#5 $(\mathrm{P}=0.036)$, \#7 $(\mathrm{P}<0.001)$, \#8 $(\mathrm{P}=0.045)$, \#10R $(\mathrm{P}=0.042)$, \#10L $(\mathrm{P}<0.001), \# 11(\mathrm{P}<0.001)$ and \#12 $(\mathrm{P}=0.018)$. Station \#7 was omitted at a similar rate in both groups (22.2\% for VATS-lobectomy and $22.6 \%$ for TORAlobectomy) (see Table S1).

\section{Lobectomy-related LND}

\section{Right upper lobe (RUL)}

In the TORA-lobectomy and VATS-lobectomy groups, 
Table 1 Patients demographics

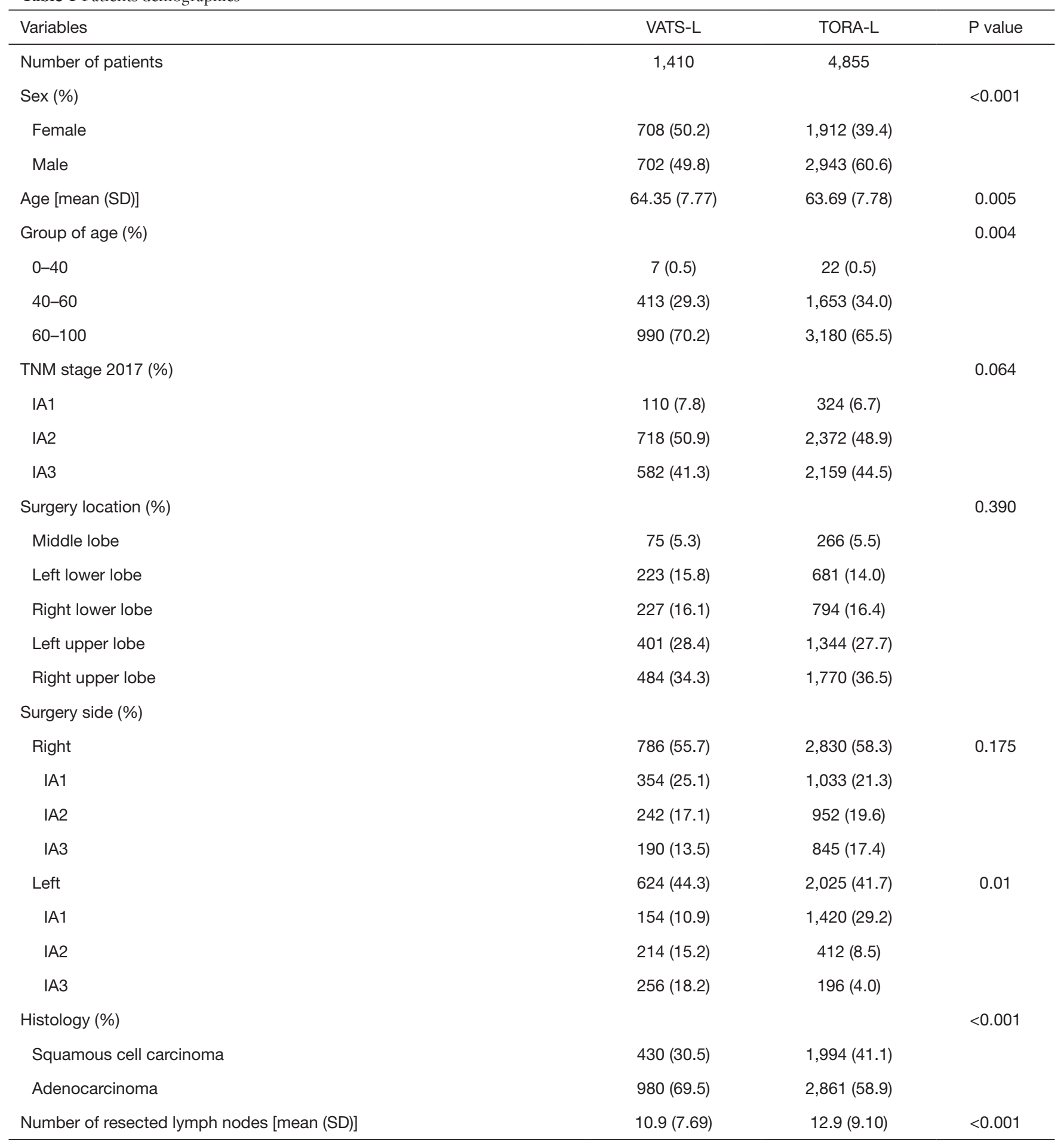

VATS-L, video-assisted thoracic surgery lobectomy; TORA-L, open thoracotomy lobectomy. 
the percentages of RUL lobectomy were $36.5 \%$ and $34.3 \%$ respectively. In the TORA-lobectomy group more lymph nodes were removed on average within groups \#7 ( $\mathrm{P}=0.001$ ), \#8 $(\mathrm{P}=0.016)$, and \#10R $(\mathrm{P}<0.001)$. Contrarily, in the VATSlobectomy group, more nodes were removed within station \#3p $(\mathrm{P}=0.044)$ (Table 2).

\section{Right lower lobe (RLL)}

In the TORA-lobectomy and VATS-lobectomy groups, the percentages of RLL lobectomy were $16.4 \%$ and $16.1 \%$, respectively. In the TORA-lobectomy group, more lymph nodes were statistically removed at station \#3a $(\mathrm{P}=0.009)$. No statistical differences were found between the groups within the remaining lymph node stations (Table 2).

\section{Left upper lobe (LUL)}

In the TORA-lobectomy and VATS-lobectomy groups, the percentages of LUL lobectomy were $27.7 \%$ and $28.4 \%$, respectively. In the TORA-lobectomy group, more lymph nodes were removed on average from the stations: \#4L $(\mathrm{P}<0.001)$, \#9 $(\mathrm{P}=0.03)$ and \#10L $(\mathrm{P}<0.001)$. In the VATSlobectomy group, more nodes were removed from stations \#2L $(\mathrm{P}=0.01)$ and \#8 ( $\mathrm{P}=0.002)$ (Table 2$)$.

\section{Left lower lobe (LLL)}

In the TORA-lobectomy and VATS-lobectomy groups, the percentages of LLL lobectomy were $14.0 \%$ and $15.8 \%$, respectively. In the TORA-lobectomy group, more nodes were statistically removed from the stations: \#5 ( $\mathrm{P}=0.009)$, \#6 $(\mathrm{P}=0.01)$ and \#10L $(\mathrm{P}=0.001)$. However, In the VATS-L group, more nodes were removed from the stations: \#2L $(\mathrm{P}=0.001), \# 7(\mathrm{P}=0.026)$ and \#8 $(\mathrm{P}=0.015)$ (Table 2).

\section{Complications}

All complications were divided to early and late period according to the learning curve. In the early period, the complication interval in the TORA-L and VATS-L groups was $34.2 \%$ and $16.3 \%$, respectively $(\mathrm{P}=0.001)$, while in the later period, $28.4 \%$ and $7.3 \%(\mathrm{P}=0.001)$, respectively. Among the serious complications later statistically significant differences were found in relation to: bleeding $(2.7 \%$ vs. $1.3 \%$, $\mathrm{P}=0.01$ ), prolonged air leakage ( $18.5 \%$ vs. $15.7 \%, \mathrm{P}=0.05)$, atrial fibrillation $(18.4 \%$ vs. $9.7 \%, \mathrm{P}<0.01)$, pneumonia ( $16.3 \%$ vs. $6.7 \%, \mathrm{P}=0.001)$ and prolonged intubation ( $4.8 \%$ vs. $0.8 \%, \mathrm{P}<0.01$ ). During the surgery, in a case of a technique switch from VATS-L to TORA-L it was counted as open lobectomy. The conversion rate was: $30 \%$ during the early period and $18 \%$ in the late period. Also, early, and late periods did not differ in long term results significantly. Thus, we decided to analyze long term results of these subgroups collectively. Detailed data is presented in Table 3.

\section{Lobectomy-related survival}

The 3- and 5-year survivals showed differences in both groups depending on the location of lobectomy (Table 4; Figure 1). Significant differences were found in the case of LLL and LUL lobectomies. Considering all locations, the 3- and 5-year survivals were better in the VATS-lobectomy group $(87.2 \%$ and $78.6 \%$, respectively) compared to TORA-lobectomy (82.4\% and $73.8 \%$, respectively) $(\mathrm{P}=0.002)$ (Table 4; Figure 2). For VATS-lobectomy of LLL 3 - and 5-year survivals were $89.5 \%$ and $87.1 \%$ respectively, and for TORA-lobectomy of LLL 3- and 5-year survivals were $80.7 \%$ and $70.3 \%$ respectively $(\mathrm{P}=0.003)$. The 3 - and 5 -year survival rates were $90.9 \%$ and $75.9 \%$ respectively for VATS-lobectomy of LUL, and $82.3 \%$ and $72.3 \%$ respectively for TORA-lobectomy of LUL ( $\mathrm{P}=0.045)$. For RLL, RUL and middle lobe, the differences were not statistically significant.

\section{Multivariable analysis}

Multivariable analysis of the presented material showed significant differences of both groups [HR (95\% CI): 1.40 (1.13-1.73), $\mathrm{P}=0.002]$. Taking into account individual assessment parameters, the analysis proved that independent prognostic factors for TORA-lobectomy in relation to VATSlobectomy were: age over 60 [HR (95\% CI): 1.55 (1.17-2.05), $\mathrm{P}=0.002$ ], female [HR (95\% CI): 1.57 (1.07-2.29), $\mathrm{P}=0.020$ ], squamous cell carcinoma [HR (95\% CI): 1.63 (1.12-2.37), $\mathrm{P}=0.011$ ], LLL [HR (95\% CI): 2.69 (1.37-5.27), $\mathrm{P}=0.004$ ] and LUL [HR (95\% CI): 1.53 (1.01-2.33) P=0.047] (Table 5).

\section{Discussion}

The number of removed lymph nodes has an impact on survival. Appropriate lymphadenectomy reduces staging error and the percentage of omitted micrometastases (12). The accuracy of lymphadenectomy indicates the effectiveness of oncological treatment. The European Society of Thoracic Surgeons recommends a removal of at least six lymph nodes from hilar and mediastinal stations to define nodal staging accurately and to determine $\mathrm{pN} 0$ status (10). The average number of nodes removed during 
Table 2 Distribution of mean number of lymph nodes dissected in VATS-lobectomy and TORA-lobectomy groups depending on location of lobectomy

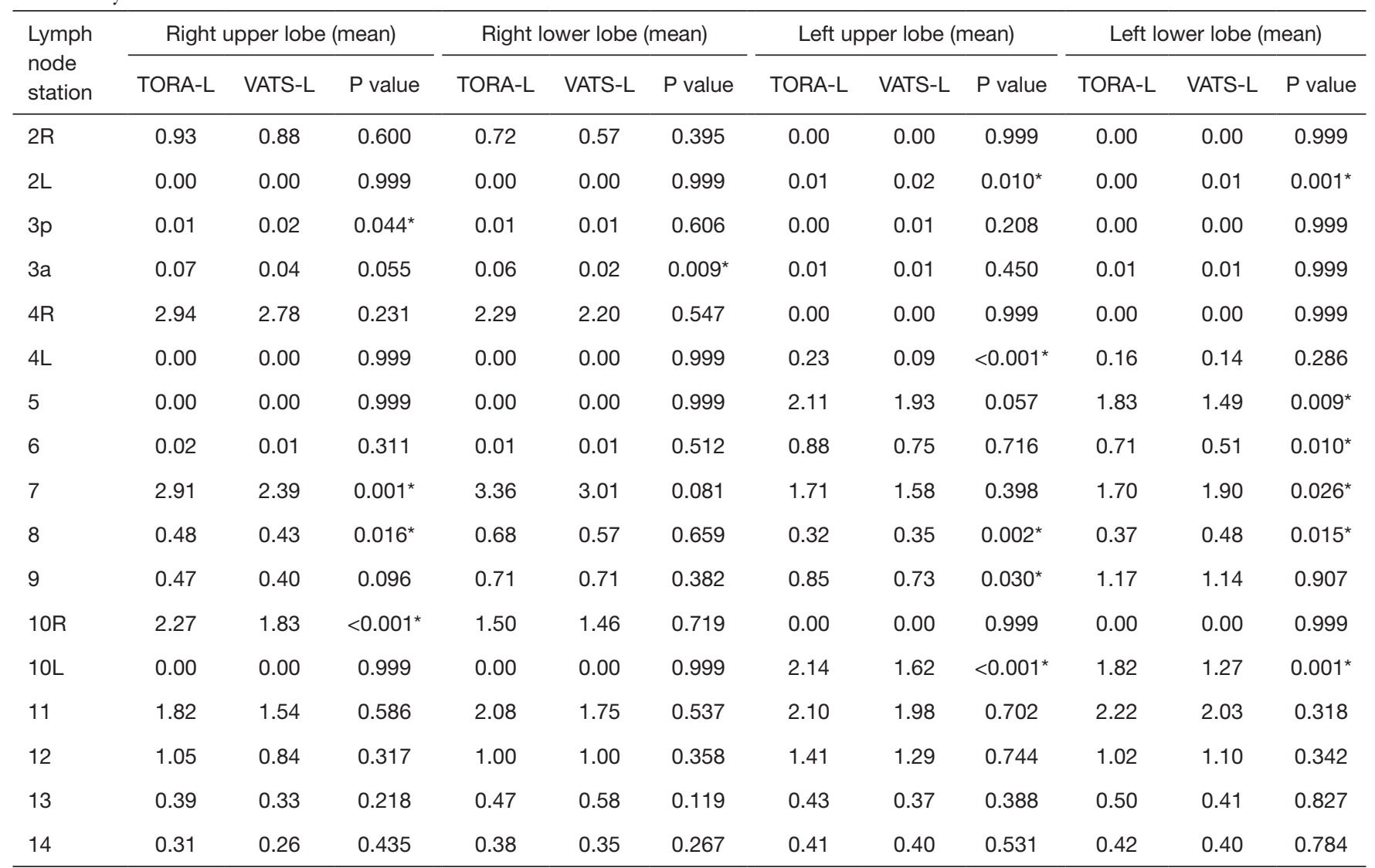

*, P<0.05. VATS-L, video-assisted thoracic surgery lobectomy; TORA-L, open thoracotomy lobectomy.

Table 3 Selected postoperative complications VATS-lobectomy versus TORA-lobectomy in early and late years of implementation of VATSlobectomy

\begin{tabular}{|c|c|c|c|c|c|c|}
\hline Complication & \multicolumn{3}{|c|}{ Early years } & \multicolumn{3}{|c|}{ Late years } \\
\hline Hemorrhage & $1.4 \%$ & $1.1 \%$ & 0.265 & $2.7 \%$ & $1.3 \%$ & 0.01 \\
\hline Prolonged air leakage & $21.3 \%$ & $16.4 \%$ & 0.453 & $18.5 \%$ & $15.7 \%$ & 0.05 \\
\hline Atrial fibrillation & $22.3 \%$ & $12.6 \%$ & $<0.01$ & $18.4 \%$ & $9.7 \%$ & $<0.01$ \\
\hline Prolonged intubation & $6.5 \%$ & $2.1 \%$ & $<0.01$ & $4.8 \%$ & $0.8 \%$ & $<0.01$ \\
\hline Bronchial fistula & $2.1 \%$ & $1.1 \%$ & 0.591 & $1.7 \%$ & $0.6 \%$ & 0.512 \\
\hline Postoperative mortality (30 days) & $4.5 \%$ & $3.2 \%$ & 0.143 & $3.8 \%$ & $0.9 \%$ & $<0.01$ \\
\hline Any postoperative complication & $34.2 \%$ & $16.3 \%$ & 0.001 & $28.4 \%$ & $7.3 \%$ & 0.001 \\
\hline
\end{tabular}

Early years: years 2007-2010, late years: years 2010-2015. VATS-L, video-assisted thoracic surgery lobectomy; TORA-L, open thoracotomy lobectomy. 
Table 4 Comparison of survivals in patients undergoing VATS-lobectomy and TORA-lobectomy

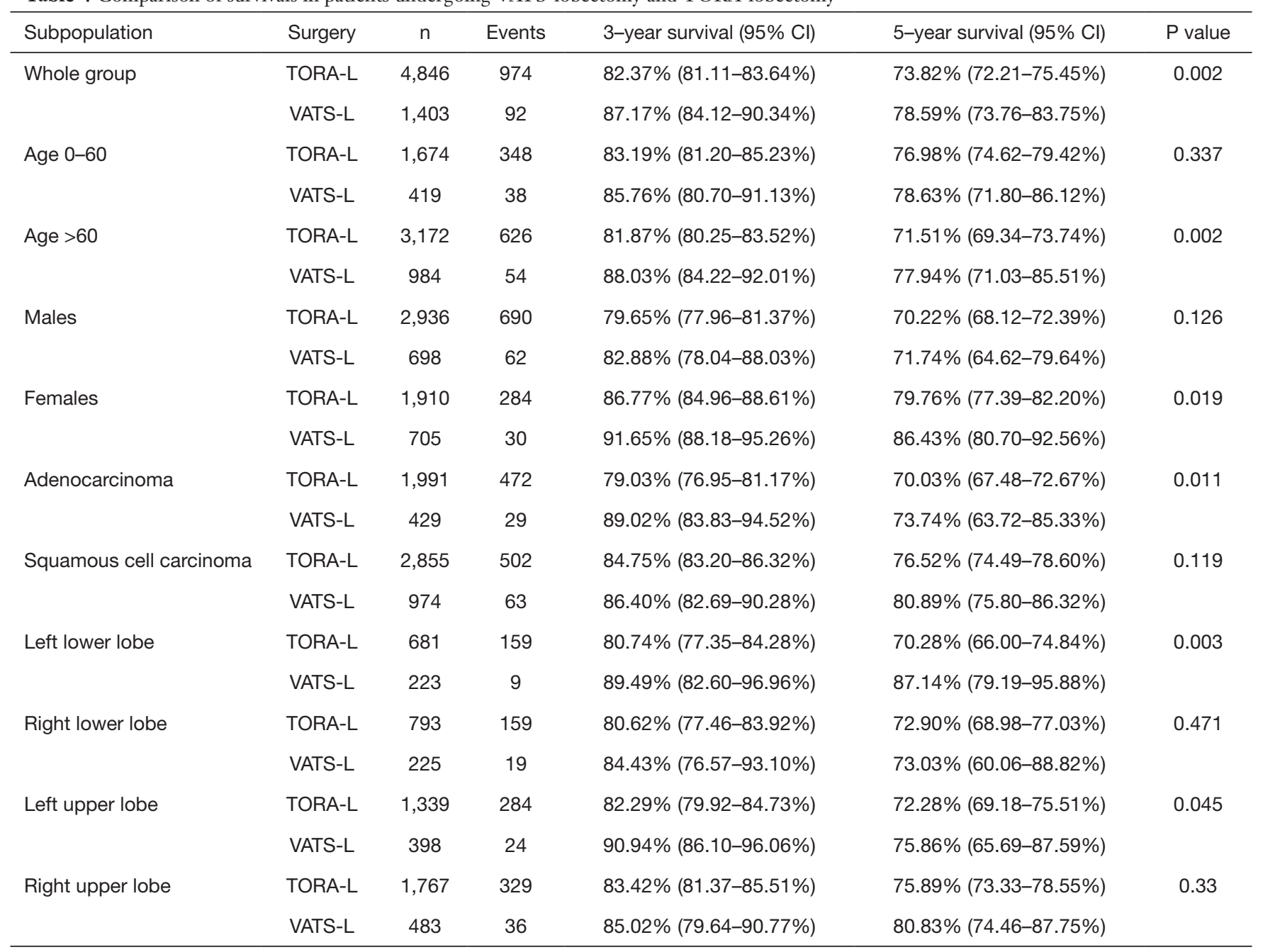

VATS-L, video-assisted thoracic surgery lobectomy; TORA-L, open thoracotomy lobectomy; n, number of patients.

VATS-lobectomy is smaller than during TORA-lobectomy (13-16). This could result in less accurate staging. But patients-with both higher number of removed lymph nodes (TORA-lobectomy 14.7 vs. VATS-lobectomy 9.9; $\mathrm{P}=0.003)$ and a higher percentage of upstaging from $\mathrm{N} 1$ to N2 (TORA-lobectomy $24.6 \%$ vs. VATS-lobectomy $10 \%$; $\mathrm{P}=0.05$ ) — did not differ in 3-year survival (13). Licht et al. presented similar conclusions: nodal upstaging to N1 in a group of 281 patients was significantly higher after TORA-lobectomy than VATS-lobectomy $(13.1 \%$ vs. $8.1 \%$ respectively, $\mathrm{P}<0.001)$, similarly upstaging to $\mathrm{N} 2(11.5 \%$ vs. $3.8 \%$ respectively; $\mathrm{P}<0.001)$. Such observations did not impact long term survival though (15). The superiority of LND over lymph node sampling (LNS) has been inconclusively discussed for years. Randomized trial of 1023 patients did not show differences in distant median survivals between LNS and LND (8.1 and 8.5 years respectively; $\mathrm{P}=0.25$ ) (14). Similarly, the meta-analysis including 6 randomized, prospective studies $(\mathrm{n}=1,791)$ showed that pooled results (OS, local recurrence rate and distant metastasis rate) were similar between LNS and LND in early-stage lung cancer patients [HR (95\% CI): 0.77 (0.55-1.08); $\mathrm{P}=0.13)$ ] (17).

In our study, we found significant differences in the average number of lymph nodes removed in the VATSlobectomy and TORA-lobectomy groups (10.9 vs. 12.9 respectively, $\mathrm{P}<0.001)$. According to many studies these are acceptable values for proper lymphadenectomy (12). In the TORA-lobectomy group more lymph nodes were removed from following stations: \#2R, \#3, \#3p, \#4R, \#4L, \#5, \#7, \#8, \#10R, \#10L, \#11 and \#12. This might be because surgeons 
A

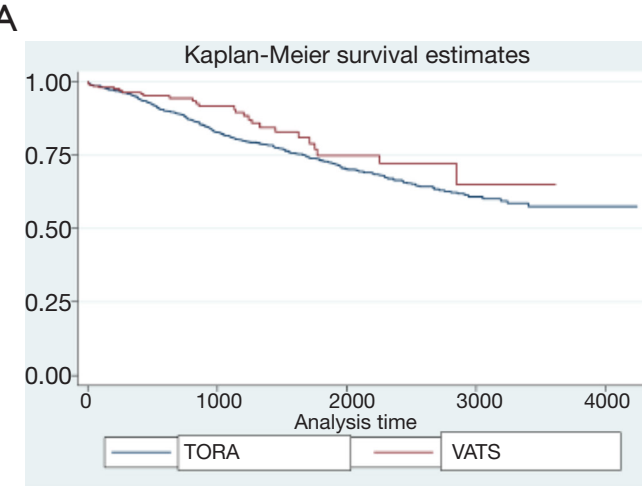

B

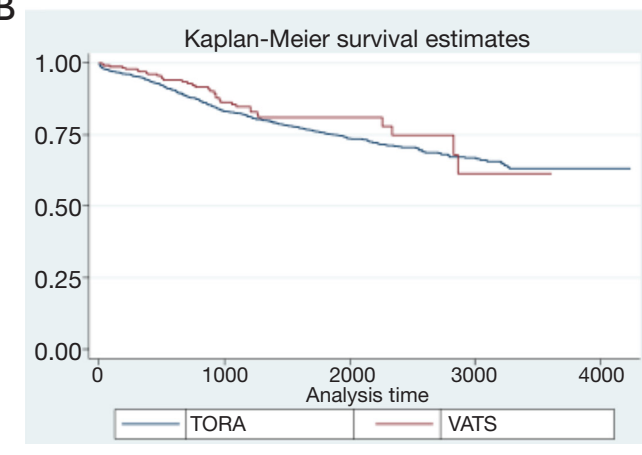

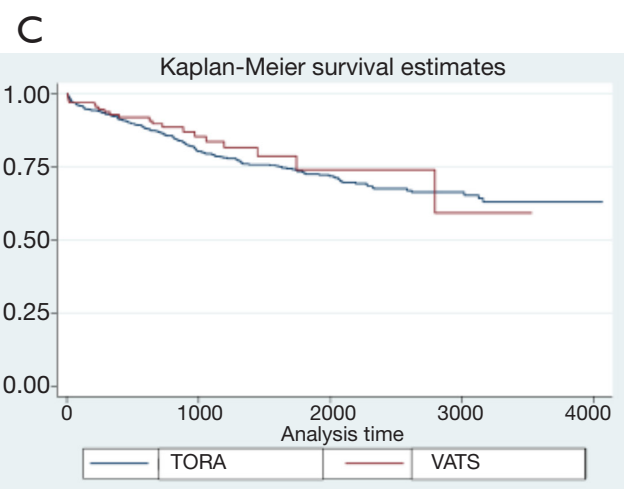

D

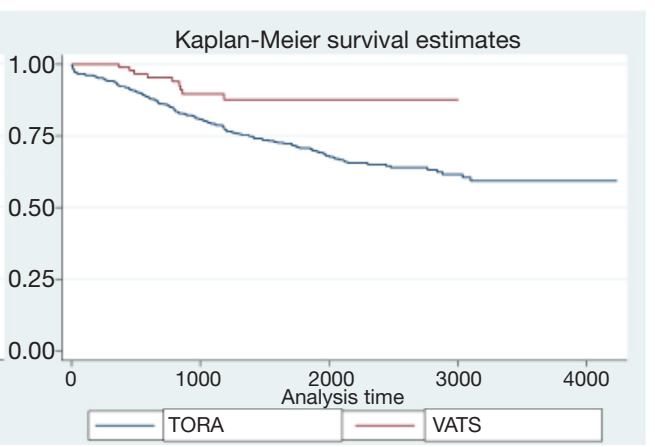

Figure 1 Overall survival of patients in group VATS and TORA depending on surgery: (A) right lower lobe $(\mathrm{P}=0.471)$, (B) right upper lobe $(\mathrm{P}=0.33)$, (C) left lower lobe $(\mathrm{P}=0.003)$, (D) left upper lobe ( $\mathrm{P}=0.045)$. TORA, open thoracotomy; VATS, video-assisted thoracic surgery.

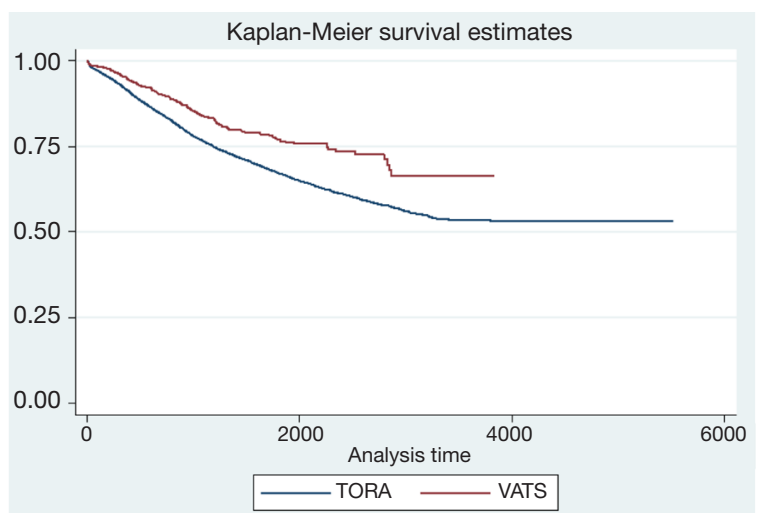

Figure 2 Overall survival curves of VATS and TORA for all eligible cases $(\mathrm{P}=0.002)$. TORA, open thoracotomy; VATS, videoassisted thoracic surgery.

performing VATS-Lobectomies consider the intervention as minimally invasive, avoiding deeper penetration of mediastinum. Surgeons may not have the ability to perform systematic lymphadenectomy in VATS-lobectomy or ignore its importance for various reasons (low tumor stage,
Table 5 Multivariable analysis of variables associated with overall survival

\begin{tabular}{lcc}
\hline Variable & $\mathrm{HR}(95 \% \mathrm{Cl})$ & $\mathrm{P}$ value \\
\hline Whole dataset & $1.40(1.13-1.73)$ & 0.002 \\
Age 0-60 & $1.18(0.84-1.65)$ & 0.338 \\
Age $>60$ & $1.55(1.17-2.05)$ & 0.002 \\
Males & $1.23(0.94-1.59)$ & 0.127 \\
Females & $1.57(1.07-2.29)$ & 0.020 \\
Squamous cell carcinoma & $1.63(1.12-2.37)$ & 0.011 \\
Adenocarcinoma & $1.23(0.95-1.61)$ & 0.120 \\
Left lower lobe & $2.69(1.37-5.27)$ & 0.004 \\
Right lower lobe & $1.19(0.74-1.93)$ & 0.471 \\
Left upper lobe & $1.53(1.01-2.33)$ & 0.047 \\
Right upper lobe & $1.19(0.84-1.68)$ & 0.331 \\
\hline
\end{tabular}

potential damage to vital organs, etc.) (18).

Lobe-specific nodal sampling (LSLNS) is a lymphadenectomy alternative, involving the removal of 
nodes depending on the location of lung cancer. In upper lobes, it is necessary to remove upper mediastinal nodes without subcarinal lymph nodes (\#7). In lower and middle lobes not only, lower mediastinal nodes are resected but also group \#7 lymph nodes. Such lymphadenectomy results in no significant difference in survival or cancer recurrence (19). LSLNS is particularly recommended for early lung cancer (20). The LSLNS concept results from typical lymphatic drainage. In the study of Haruki et al., nodal metastases in station \#7 in case of upper lobes cancers were notably rarer than in case of lower and middle lobes. Noteworthy, metastases to the lower mediastinal nodes (\#8, \#9) from upper lobes cancers were not found (21). But a recent study showed that the proportion of subcarinal lymph nodes involvement was also high in the right $(21.8 \%)$ and left (25.8\%) upper lobe tumors (22). Similarly, Eckardt et al. concluded that lymph nodes \#7 should be removed in any location of lobectomy to avoid understaging (23).

In our study, lymph nodes of station \#7 in the TORAlobectomy and VATS-lobectomy groups were not removed in $22.6 \%$ and $22.2 \%$ of patients, respectively. VATSlobectomy resulted in lower mean number of removed station \#7 lymph nodes in case of RUL $(\mathrm{P}=0.001)$ and higher mean number in case of LLL $(\mathrm{P}=0.026)$. Other locations did not differ significantly. Also, VATS-lobectomy resulted in higher mean number of removed station \#8 lymph nodes in case of LUL and LLL ( $\mathrm{P}=0.002$ and $\mathrm{P}=0.015$, respectively) (Table 2). Zhang et al. showed differences between VATSlobectomy and TORA-lobectomy regarding the number of station \#7 lymph nodes collected especially on the left side (7.25 vs. 8.78, respectively; $\mathrm{P}<0.01)$ (24).

The percentage of VATS-lobectomy complications in literature vary from $5.1 \%$ to $34.2 \%$ (25). Our study confirmed that VATS-lobectomy is safer than TORAlobectomy. However, the percentage of complications depends on the learning curve and decreases with gained experience. Quality of lymphadenectomy is also affected by the learning curve (26). In the present study, the percentage of complications in the early and late periods were $16.3 \%$ vs. $34.2 \%$ and $7.3 \%$ vs. $28.4 \%$, respectively. Park et al. showed that atrial fibrillation, atelectasis, prolonged air leakage, pneumonia, necessity of transfusion, and renal failure are much more common in the TORA-lobectomy group. Moreover, mortality among patients who underwent thoracotomy was higher than among patients after VATS (5\% vs. 3\%) (6). Paul et al. came to the same conclusion (27). Some authors achieved even lower early mortality rates in VATS-lobectomy (90-day mortality: $0.55 \%$ ), which may reflect the importance of the learning curve (28).

Numerous prospective and retrospective studies confirmed that VATS-lobectomy in early lung cancer patients is a safer and more effective procedure than TORAlobectomy with a lower percentage of complications, shorter hospitalization, and faster postoperative rehabilitation (29-31). Paul et al. showed that VATS-lobectomy had similar overall, cancer-specific, and disease-free survivals compared with patients undergoing TORA-lobectomy (27). In addition, the study showed that during VATS surgeons resected more lymph nodes than after open surgery, but the study included only patients in the advanced stage of lung cancer. In another study, 416 patients mainly in stage I (208 patients after VATS-lobectomy and 208 undergoing TORA-lobectomy), despite having a higher number of removed lymph nodes after open thoracotomy, did not differ in long-term survival (32). Multivariate analyses of OS and DFS confirmed the noninferiority of non-rib-spreading technique. Moreover, one of the meta-analyses, which was carried out on patients who underwent VATS-lobectomy $(\mathrm{n}=2,106)$ and TORA-lobectomy $(\mathrm{n}=2,661)$ did not show difference in 5-year survivals (ranges, 62-97\% vs. 58-97\%, respectively). VATS-lobectomy improved results only by $5 \%$ compared to TORA-lobectomy (33). Another meta-analysis $(n=6,370)$ showed that results after VATS-lobectomy achieve even higher improvement after 4 years of followup and approximate to $17 \%$. Moreover, through the 5 years after operation, patients undergoing VATS-lobectomy have achieved higher percentage of OS in comparison of TORAlobectomy each year, but only OS rate after 4-year followup was statistically significant (25). Results of another study showed better 5-year overall and disease-free survival in the group of patients after VATS-lobectomy (34). On the other hand, the Kaplan-Meier 3-year survival in the study of Merritt et al. was similar between two groups (16).

Our study confirmed this correlation, because the 3and 5 -year survivals were significantly better in the VATSlobectomy group compared to TORA-lobectomy (Figure 2). What is more interesting, the differences between groups in survivals were only significant in lobectomies on the left side (Figure 1, Table 4). The results can be explained by a larger percentage of lesions operated on the left side in stage IA1 (29.2\%) by the VATS-lobectomy compared to TORA-lobectomy (18.0\%). Contrarily, the TORAlobectomy group was dominated by stage IA2 (18.2\%). The differences in the distribution of tumor stage on the right side were not significant.

The presented study has several limitations. The major 
limitation is the retrospective nature of the study, which always causes inadvertent distortion of the results. Another limitation is the material that is based only on the group of patients with pathologically confirmed I stage. As a result, the presented study does not include the significant population with an upstaging phenomenon. In addition, pT1a, pT1b and pT1c were analyzed collectively, which could have affected the diversity of distant results. Surgeons may have been biased as e.g. more percentage of IA1 stage was present in VATS-L group on the left side. A significant limitation of the study is a multicenter analysis, which causes heterogeneity of the entire analyzed group of patients. The surgeries were performed by many surgeons, possibly differing in preferred surgical access and different approaches to lymphadenectomy invasiveness. Similarly, specimen analysis by numerous pathologists may have varied from one center to another. But it also improves the generalizability of our findings. Like most similar analyses assessing the number of removed lymph nodes may be questionable due to frequent single defragmentation of the lymph node and an increase in the total number of them. The study also covered the initial period of VATS-lobectomy development in Poland, which according to the learning curve, affected the results. The first VATS interventions in Poland began in 2002. Initially, the development of this surgical technique was slow, and the speed of VATSlobectomy implementation varied between centers, which significantly lengthened the learning curve. Nowadays most procedures in the early stages of lung cancer are performed using a minimally invasive technique.

\section{Conclusions}

The results of our study showed that the number of lymph nodes removed during VATS-lobectomy is lower than in the TORA-lobectomy group. Nevertheless, this has no direct impact on long-term survival, which was significantly better in the VATS-lobectomy group. The study found differences in survival for individual locations of lobectomy. Better results were obtained on the left side.

\section{Acknowledgments}

Funding: None.

\section{Footnotes}

Reporting Checklist: The authors have completed the
STROBE reporting checklist. Available at http://dx.doi. org/10.21037/jtd-20-2251

Data Sharing Statement: Available at http://dx.doi. org/10.21037/jtd-20-2251

Peer Review File: Available at http://dx.doi.org/10.21037/jtd20-2251

Conflicts of Interest: All authors have completed the ICMJE uniform disclosure form (available at http://dx.doi. org/10.21037/jtd-20-2251). The authors have no conflicts of interest to declare.

Ethical Statement: The authors are accountable for all aspects of the work in ensuring that questions related to the accuracy or integrity of any part of the work are appropriately investigated and resolved. The study was conducted in accordance with the Declaration of Helsinki (as revised in 2013). The study was approved by the ethics committee of the National Research Institute of Chest Diseases, Warsaw, Poland (KB-89/2020); and written consent was obtained from all patients.

Open Access Statement: This is an Open Access article distributed in accordance with the Creative Commons Attribution-NonCommercial-NoDerivs 4.0 International License (CC BY-NC-ND 4.0), which permits the noncommercial replication and distribution of the article with the strict proviso that no changes or edits are made and the original work is properly cited (including links to both the formal publication through the relevant DOI and the license). See: https://creativecommons.org/licenses/by-nc-nd/4.0/.

\section{References}

1. World Health O. Global status report on noncommunicable diseases 2014. vol WHO/NMH/ NVI/15.1. Geneva: World Health Organization; 2014.

2. International Agency for Research on Cancer WHO. GLOBOCAN 2012: Estimated Cancer Incidence, Mortality and Prevalence Worldwide in 20122012. https://gco.iarc.fr/. Accessed 11 May 2020.

3. National Cancer Database. Incidence and mortality of cancer in Poland. 2015. Available online: http://onkologia. org.pl/raporty/. Accessed 11 May 2020.

4. Henschke CI, Yankelevitz DF, Libby DM, et al. Survival of patients with stage I lung cancer detected on CT 
screening. N Engl J Med 2006;355:1763-71.

5. Howington JA, Blum MG, Chang AC, et al. Treatment of stage I and II non-small cell lung cancer: Diagnosis and management of lung cancer, 3rd ed: American College of Chest Physicians evidence-based clinical practice guidelines. Chest 2013;143:e278S-e313S.

6. Park BJ. Is surgical morbidity decreased with minimally invasive lobectomy? Cancer J 2011;17:18-22.

7. Mathisen DJ. Is video-assisted thoracoscopic lobectomy inferior to open lobectomy oncologically? Ann Thorac Surg 2013;96:755-6.

8. Osarogiagbon RU, Allen JW, Farooq A, et al. Objective review of mediastinal lymph node examination in a lung cancer resection cohort. J Thorac Oncol 2012;7:390-6.

9. Osarogiagbon RU, Yu X. Nonexamination of lymph nodes and survival after resection of non-small cell lung cancer. Ann Thorac Surg 2013;96:1178-89.

10. Lardinois D, De Leyn P, Van Schil P, et al. ESTS guidelines for intraoperative lymph node staging in non-small cell lung cancer. Eur J Cardiothorac Surg 2006;30:787-92.

11. Asamura H, Chansky K, Crowley J, et al. The International Association for the Study of Lung Cancer Lung Cancer Staging Project: Proposals for the Revision of the N Descriptors in the Forthcoming 8th Edition of the TNM Classification for Lung Cancer. J Thorac Oncol 2015;10:1675-84.

12. Ludwig MS, Goodman M, Miller DL, et al. Postoperative survival and the number of lymph nodes sampled during resection of node-negative non-small cell lung cancer. Chest 2005;128:1545-50.

13. Boffa DJ, Kosinski AS, Paul S, et al. Lymph node evaluation by open or video-assisted approaches in 11,500 anatomic lung cancer resections. Ann Thorac Surg 2012;94:347-53; discussion 353.

14. Darling GE, Allen MS, Decker PA, et al. Randomized trial of mediastinal lymph node sampling versus complete lymphadenectomy during pulmonary resection in the patient with N0 or N1 (less than hilar) non-small cell carcinoma: results of the American College of Surgery Oncology Group Z0030 Trial. J Thorac Cardiovasc Surg 2011;141:662-70.

15. Licht PB, Jorgensen OD, Ladegaard L, et al. A national study of nodal upstaging after thoracoscopic versus open lobectomy for clinical stage I lung cancer. Ann Thorac Surg 2013;96:943-9; discussion 949-50.

16. Merritt RE, Hoang CD, Shrager JB. Lymph node evaluation achieved by open lobectomy compared with thoracoscopic lobectomy for N0 lung cancer. Ann Thorac Surg 2013;96:1171-7.

17. Huang X, Wang J, Chen Q, et al. Mediastinal lymph node dissection versus mediastinal lymph node sampling for early stage non-small cell lung cancer: a systematic review and meta-analysis. PLoS One 2014;9:e109979.

18. Zhang Z, Zhang Y, Feng H, et al. Is video-assisted thoracic surgery lobectomy better than thoracotomy for early-stage non-small-cell lung cancer? A systematic review and metaanalysis. Eur J Cardiothorac Surg 2013;44:407-14.

19. Shapiro M, Kadakia S, Lim J, et al. Lobe-specific mediastinal nodal dissection is sufficient during lobectomy by video-assisted thoracic surgery or thoracotomy for early-stage lung cancer. Chest 2013;144:1615-21.

20. Han H, Chen H. Selective lymph node dissection in early-stage non-small cell lung cancer. J Thorac Dis 2017;9:2102-7.

21. Haruki T, Aokage K, Miyoshi T, et al. Mediastinal nodal involvement in patients with clinical stage I non-small-cell lung cancer: possibility of rational lymph node dissection. J Thorac Oncol 2015;10:930-6.

22. Fang L, Xu J, Ye B, et al. Is lobe specific lymph node dissection adequate for $\mathrm{cN} 0-1$ non-small cell lung cancer? J Cardiothorac Surg 2020;15:46.

23. Eckardt J, Jakobsen E, Licht PB. Subcarinal Lymph Nodes Should be Dissected in All Lobectomies for Non-Small Cell Lung Cancer-Regardless of Primary Tumor Location. Ann Thorac Surg 2017;103:1121-5.

24. Zhang J, Wu Y, Li H, et al. Retrospective study on videoassisted vs. open mediastinal lymphadenectomy for nonsmall cell lung cancer: a propensity-matched analysis. J Thorac Dis 2018;10:1884-90.

25. Whitson BA, Groth SS, Duval SJ, et al. Surgery for earlystage non-small cell lung cancer: a systematic review of the video-assisted thoracoscopic surgery versus thoracotomy approaches to lobectomy. Ann Thorac Surg 2008;86:200816; discussion 2016-8.

26. Lee PC, Kamel M, Nasar A, et al. Lobectomy for NonSmall Cell Lung Cancer by Video-Assisted Thoracic Surgery: Effects of Cumulative Institutional Experience on Adequacy of Lymphadenectomy. Ann Thorac Surg 2016;101:1116-22.

27. Paul S, Isaacs AJ, Treasure T, et al. Long term survival with thoracoscopic versus open lobectomy: propensity matched comparative analysis using SEER-Medicare database. Bmj 2014;349:g5575.

28. Infante MV, Benato C, Silva R, et al. What counts more: the patient, the surgical technique, or the hospital? A 
multivariable analysis of factors affecting perioperative complications of pulmonary lobectomy by video-assisted thoracoscopic surgery from a large nationwide registry. Eur J Cardiothorac Surg 2019;56:1097-103.

29. Onaitis MW, Petersen RP, Balderson SS, et al. Thoracoscopic lobectomy is a safe and versatile procedure: experience with 500 consecutive patients. Ann Surg 2006;244:420-5.

30. Swanson SJ, Herndon JE 2nd, D'Amico TA, et al. Videoassisted thoracic surgery lobectomy: report of CALGB 39802--a prospective, multi-institution feasibility study. J Clin Oncol 2007;25:4993-7.

31. Nwogu CE, D'Cunha J, Pang H, et al. VATS lobectomy has better perioperative outcomes than open lobectomy:

Cite this article as: Dziedzic DA, Zbytniewski M, Gryszko GM, Cackowski MM, Langfort R, Orlowski TM; on behalf of the Polish Lung Cancer Study Group (PLCSG). Videoassisted versus open thoracotomy lobectomy: comparison on lymphadenectomy and survival in early stage of lung cancer. J Thorac Dis 2021;13(1):101-112. doi: 10.21037/jtd-20-2251
CALGB 31001, an ancillary analysis of CALGB 140202 (Alliance). Ann Thorac Surg 2015;99:399-405.

32. Lee PC, Nasar A, Port JL, et al. Long-term survival after lobectomy for non-small cell lung cancer by video-assisted thoracic surgery versus thoracotomy. Ann Thorac Surg 2013;96:951-60; discussion 960-1.

33. Taioli E, Lee DS, Lesser M, et al. Long-term survival in video-assisted thoracoscopic lobectomy vs. open lobectomy in lung-cancer patients: a meta-analysis. Eur J Cardiothorac Surg 2013;44:591-7.

34. Oda R, Okuda K, Osaga S, et al. Long-term outcomes of video-assisted thoracoscopic surgery lobectomy vs. thoracotomy lobectomy for stage IA non-small cell lung cancer. Surg Today 2019;49:369-77. 
Table S1 Characteristics of lymph node dissection depending on lymph node station.

\begin{tabular}{|c|c|c|c|c|}
\hline LN station & Number of LN resected & VATS-L (\%) & TORA-L (\%) & $p$-value \\
\hline \multirow[t]{3}{*}{$2 \mathrm{R}$} & 0 & $1141(80.9)$ & $3841(79.1)$ & 0.013 \\
\hline & $1-4$ & 247 (17.5) & $870(17.9)$ & \\
\hline & $\geq 5$ & $22(1.6)$ & $144(3.0)$ & \\
\hline \multirow[t]{3}{*}{$2 \mathrm{~L}$} & 0 & $1397(99.1)$ & 4789 (98.6) & 0.432 \\
\hline & $1-4$ & $12(0.9)$ & $61(1.3)$ & \\
\hline & $\geq 5$ & $1(0.1)$ & $5(0.1)$ & \\
\hline \multirow[t]{3}{*}{3} & 0 & $1392(98.7)$ & 4635 (95.5) & $<0.001$ \\
\hline & $1-4$ & $18(1.3)$ & $202(4.2)$ & \\
\hline & $\geq 5$ & $0(0.0)$ & $18(0.4)$ & \\
\hline \multirow[t]{2}{*}{$3 p$} & 0 & 1400 (99.3) & $4842(99.7)$ & 0.031 \\
\hline & $1-4$ & $10(0.7)$ & $13(0.3)$ & \\
\hline \multirow[t]{3}{*}{$3 a$} & 0 & $1393(98.8)$ & $4758(98.0)$ & 0.079 \\
\hline & $1-4$ & $17(1.2)$ & $88(1.8)$ & \\
\hline & $\geq 5$ & $0(0.0)$ & $9(0.2)$ & \\
\hline \multirow[t]{3}{*}{$4 \mathrm{R}$} & 0 & $770(54.6)$ & $2588(53.3)$ & 0.001 \\
\hline & $1-4$ & $510(36.2)$ & 1639 (33.8) & \\
\hline & $\geq 5$ & $130(9.2)$ & $628(12.9)$ & \\
\hline \multirow[t]{3}{*}{$4 \mathrm{~L}$} & 0 & $1364(96.7)$ & 4560 (93.9) & $<0.001$ \\
\hline & $1-4$ & $42(3.0)$ & $255(5.3)$ & \\
\hline & $\geq 5$ & $4(0.3)$ & $40(0.8)$ & \\
\hline \multirow[t]{3}{*}{5} & 0 & $913(64.8)$ & 3221 (66.3) & 0.036 \\
\hline & $1-4$ & $450(31.9)$ & $1416(29.2)$ & \\
\hline & $\geq 5$ & $47(3.3)$ & $218(4.5)$ & \\
\hline \multirow[t]{3}{*}{6} & 0 & $1170(83.0)$ & 4060 (83.6) & 0.357 \\
\hline & $1-4$ & $228(16.2)$ & $736(15.2)$ & \\
\hline & $\geq 5$ & $12(0.9)$ & $59(1.2)$ & \\
\hline \multirow[t]{3}{*}{7} & 0 & $313(22.2)$ & 1096 (22.6) & $<0.001$ \\
\hline & $1-4$ & $924(65.5)$ & 2864 (59.0) & \\
\hline & $\geq 5$ & $173(12.3)$ & $895(18.4)$ & \\
\hline \multirow[t]{3}{*}{8} & 0 & 1060 (75.2) & 3640 (75.0) & 0.045 \\
\hline & $1-4$ & $342(24.3)$ & 1148 (23.6) & \\
\hline & $\geq 5$ & $8(0.6)$ & $67(1.4)$ & \\
\hline \multirow[t]{3}{*}{9} & 0 & $870(61.7)$ & 2840 (58.5) & 0.097 \\
\hline & $1-4$ & $523(37.1)$ & $1949(40.1)$ & \\
\hline & $\geq 5$ & $17(1.2)$ & $66(1.4)$ & \\
\hline \multirow[t]{3}{*}{$10 R$} & 0 & $828(58.7)$ & 2835 (58.4) & 0.042 \\
\hline & $1-4$ & $503(35.7)$ & $1656(34.1)$ & \\
\hline & $\geq 5$ & 79 (5.6) & 364 (7.5) & \\
\hline \multirow[t]{3}{*}{$10 \mathrm{~L}$} & 0 & 971 (68.9) & 3377 (69.6) & $<0.001$ \\
\hline & $1-4$ & $400(28.4)$ & $1213(25.0)$ & \\
\hline & $\geq 5$ & $39(2.8)$ & 265 (5.5) & \\
\hline \multirow[t]{3}{*}{11} & 0 & $377(26.7)$ & $1602(33.0)$ & $<0.001$ \\
\hline & $1-4$ & 919 (65.2) & 2657 (54.7) & \\
\hline & $\geq 5$ & $114(8.1)$ & $596(12.3)$ & \\
\hline \multirow[t]{3}{*}{12} & 0 & 988 (70.1) & $3322(68.4)$ & 0.018 \\
\hline & $1-4$ & $356(25.2)$ & 1205 (24.8) & \\
\hline & $\geq 5$ & $66(4.7)$ & $328(6.8)$ & \\
\hline \multirow[t]{3}{*}{13} & 0 & $1284(91.1)$ & 4440 (91.5) & 0.304 \\
\hline & $1-4$ & $104(7.4)$ & 317 (6.5) & \\
\hline & $\geq 5$ & $22(1.6)$ & $98(2.0)$ & \\
\hline
\end{tabular}

LN - lymph nodes, VATS-L - video-assisted thoracic surgery lobectomy, TORA-L - thoracotomy lobectomy. 